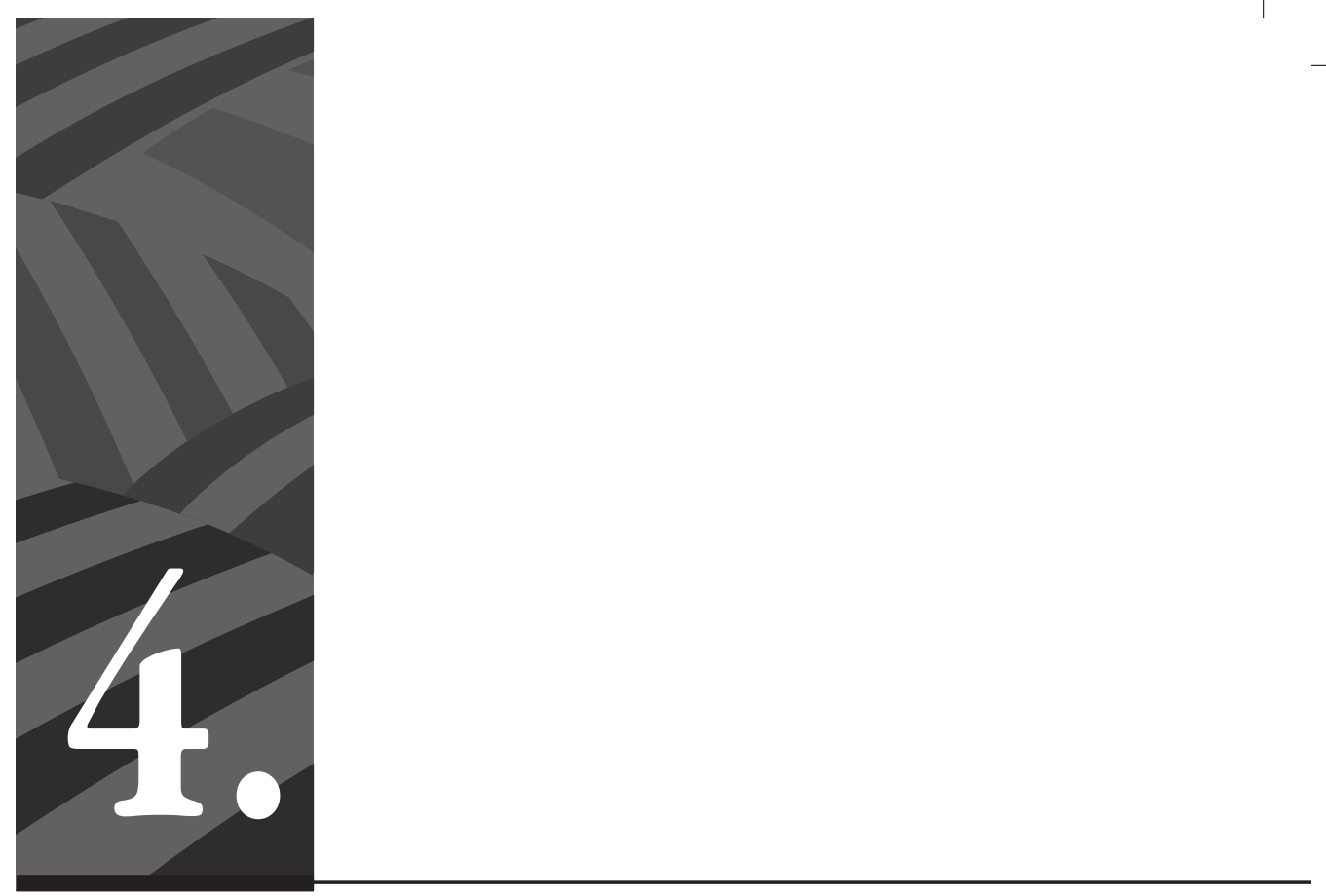

Inclusión LGBTI en Colombia:

reflexión jurídica y social 


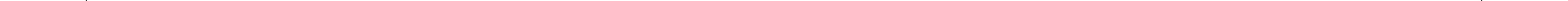




\title{
Inclusión LGBTI en Colombia: reflexión jurídica y social
}

\author{
Por María Susana Marlés Herrera ${ }^{* *}$ Nahín Numa Sanjuán ${ }^{* * *}$, Sergio Alonso Jácome Jácome ${ }^{* * * *}$, \\ Ludy Alexandra Montañez Gélvez ${ }^{* * * *}$, Wilkar Simón Mendoza Chacón ${ }^{* * * * *}$ y Johan Andrés \\ Estupiñán Silva ${ }^{* * * * * *}$
}

Resumen: Este documento promueve la reflexión acerca de la importancia de coexistir en una sociedad libre, equitativa, digna e igualitaria ante la norma. La investigación que lo consolidó tiene un diseño cualitativo, un método hermenéutico y se soportó en el paradigma sociojurídico. Asimismo, delibera sobre la imperiosa necesidad de generar hoy en día interlocución múltiple en el escenario social, bajo una perspectiva que permita observar con flexibilidad sus variadas aristas. El razonamiento desde los derechos permite aunar esfuerzos para el reconocimiento total del conglomerado humano, aún más cuando se trata de la población LGBTI (lesbianas, gais, bisexuales,

* $\quad$ El presente artículo hace parte de los resultados del proyecto titulado "Inclusión de la comunidad LGBTI en la búsqueda de una paz inalterable en Colombia”, el cual lleva más de un año en proceso, gracias a los docentes y a un grupo de estudiantes integrantes del Semillero de Investigación en Derechos Humanos y Derecho Internacional Humanitario (SINDEH) del programa de Derecho de la Universidad Simón Bolívar, sede Cúcuta.

** Magíster en Ciencia Política, Universidad de Los Andes, Bogotá. Docente investigadora, Universidad Simón Bolívar, sede Cúcuta. Miembro del grupo de investigación Altos Estudios de Frontera (Alef). Líder del proyecto del que surge este artículo. Correo electrónico: m.marles01@unisimonbolivar.edu.co

*** Magíster en Planificación Global, Universidad Pedagógica Experimental Libertador, República Bolivariana de Venezuela. Docente investigador, Universidad Simón Bolívar, sede Cúcuta. Miembro del grupo de investigación Alef. Correo electrónico: n.numauniversidadsimonbolivar@gmail.com

**** Magíster en Derecho Administrativo, Universidad Simón Bolívar. Docente investigador, Universidad Simón Bolívar, sede Cúcuta. Miembro del grupo de investigación Alef. Correo electrónico: s.jacome@unisimonbolivar.edu.co

***** Maestrante en Educación, Universidad Simón Bolívar, sede Cúcuta. Docente investigadora, Universidad Simón Bolívar, sede Cúcuta. Miembro del grupo de investigación Alef. Correo electrónico: 1.montanez@unisimonbolivar.edu.co

***** Estudiante de Derecho (décimo semestre), Universidad Simón Bolívar. Miembro del SINDEH. Correo electrónico: w_mendoza@unisimon.edu.co

$* * * * *$ Estudiante de Derecho (octavo semestre), Universidad Simón Bolívar. Miembro del SINDEH. Correo electrónico: j_estupinan@unisimon.edu.co 
transexuales e intersexuales), no con un interés puramente legal, sino desde la reivindicación de derechos, que son cercenados por su exclusión en la llamada hetero-normatividad. En razón a lo anterior, el documento invita a la inclusión social de la colectividad diversa sexual, con base en un acercamiento respetuoso a los avances internacionales desde los Principios de Yogyakarta, como también desde la jurisprudencia constitucional colombiana, en algunos de los muchos aspectos que conlleva la reivindicación de los derechos en procura de la seguridad jurídica de un importante sector de la población.

Palabras clave: Género, identidad sexual, orientación sexual, normativa internacional, precedente constitucional.

\section{LGBTI inclusion in Colombia: Legal-social reflection}

Abstract: This text promotes understanding about the importance of coexisting in a free, equitable, worthy and before-the-law equalitarian society from evident concepts. The research that allowed it has a qualitative design, a hermeneutic method and was based on the socio-juridical paradigm. Likewise, it deliberates about the imperative necessity of generating today a multiple interlocution into the social background, under a perspective that allows to observe with flexibility its variable edges. Reasoning, from rights, joins efforts in order to get a recognition of the whole human conglomerate, even more when referring to LGBTI (lesbians, gays, bisexuals, transsexuals and intersexual) population, not only with a purely legal interest, but from re vindication of rights, which are curtailed because of its exclusion in the so-called hetero-normativity. Therefore there exist a reflection in this manuscript, which invites to social inclusion of the sexually diverse collectivity, basing on a respectful rapprochement to the international advances from Yogyakarta Principles, as well as from the Colombian constitutional jurisprudence, in some of the many aspects that vindication of rights involves, in pursuit of the legal certainty of an important social sector.

Keywords: Gender, sexual identity, sexual orientation, international normativity, constitutional precedent.

Cómo citar este artículo: Marlés Herrera, María Susana; Sanjuán, Nahín Numa; Jácome Jácome, Sergio Alonso; Montañez Gélvez, Ludy Alexandra; Mendoza Chacón, Wilkar Simón; Estupiñán Silva, Johan Andrés (2018). Inclusión LGBTI en Colombia: reflexión jurídica y social. Revista Controversia, 211, 139-161.

Fecha de recepción: 4 de julio de 2018

Fecha de aprobación: 28 de agosto de 2018 


\section{Introducción}

$\mathrm{L}$

a reflexión en torno a los significantes inherentes a las personas, como el género, la identidad y la orientación sexual, vincula necesariamente su comprensión, lo que redunda en la inclusión desde los ámbitos social y jurídico, dado que cada uno abarca un ángulo distinto de los sujetos en particular y de los componentes propios de la persona, más aún cuando se refiere a la población de lesbianas, gais, bisexuales, transexuales e intersexuales (LGBTI). El desenvolvimiento de la sociedad en la historia visibiliza actitudes y concepciones desiguales, en la medida en que concibe dicha diversidad - y sus componentescomo propia; por ello, es necesario revisar conceptos y elementos normativos como los jurisprudenciales, nacionales e internacionales.

El proyecto, del cual resulta la presente reflexión, obtuvo varios resultados, dos de los cuales están en proceso de ser publicados como libros digitales con el sello de la Universidad Simón Bolívar, titulados Colombia y una de sus encrucijadas: la diversidad sexual y Los Derechos Humanos: consideraciones desde la deshumanización y la diversidad. Estos tratan de la revisión jurídica de la norma y jurisprudencia colombiana (105 sentencias y dos autos de la corte Constitucional colombiana), como también de la revisión de las normas internacionales, desde la última década del siglo xx y lo que va corrido del presente.

Desde lo académico, este ejercicio fue acompañado por seis organizaciones en relación con la población LGBTI (la mayoría de carácter nacional) con incidencia regional como la Fundación Censurados, Mujeres y Hombres Diversos (MHD), el Sector Diverso de Movimiento Político y Social Marcha Patriótica, el Colectivo León Zuleta, la Fundación Hoasis, la Fundación Provida, la Corporación Identidades, la Fundación Rostros Diversos LGBTI + H, las cuales brindan legitimidad a los logros alcanzados.

Con base en lo anterior, la pretensión de este manuscrito parte de la definición ilustrativa de los conceptos generales, la revisión del instrumento 
normativo de los derechos internacionales y los Principios de Yogyakarta, así como de los avances significativos logrados desde la Corte Constitucional en Colombia, gracias a su jurisprudencia que continúa en la proclama de facultades garantistas de derechos. En consecuencia, este documento brinda argumentos para aportar, desde lo jurídico, a la superación de la discriminación social de cualquier colectivo humano, menospreciado o excluido.

No pretende socavar posturas religiosas, ideológicas, incluso culturales. Intenta, eso sí, brindar algunos elementos normativos que incidan en el logro de una sociedad respetuosa de la diferencia y la diversidad. Tras dieciocho meses de indagación del tema, se puede afirmar que en Colombia existe una exigua legislación y latente debilidad en las políticas públicas frente a los mismos y que, gracias al trabajo de sus colectivos, es viable reformular las decisiones oficiales (desde el ejecutivo y el legislativo), para avanzar en el reconocimiento de derechos, en tanto garantías jurídicas respetuosas del conglomerado LGBTI.

\section{Significantes que abordan la población LGBTI}

Con el fin de dar coherencia al escrito, cabe iniciar con la definición de algunos conceptos, que pueden resultar desconocidos para muchos ciudadanos. Se busca que estos puedan proporcionar nociones que allanen representaciones sociales, ideas o imágenes que definen una realidad, que puedan trastocar - violentar, incluso- y trasgredir derechos de grupos humanos y su diversidad o, si se quiere, su especificidad particular. A pesar de ser comunes en el lenguaje castellano, no se estima una comprensión efectiva de dichos conceptos.

\section{Sexo}

$\mathrm{Al}$ indagar aspectos relevantes acerca del sexo, es importante enunciar disquisiciones referentes al mismo; una de ellas es el sexo genético, el cual obedece a una descarga genética, en la que el espermatozoide fecunda al ovocito y, de acuerdo a su carga X o Y, determina el sexo genético (Audí, 2001, p. 1). 
En relación con las personas intersexuales, estas nacen con caracteres sexuales (los genitales, las gónadas y los patrones cromosómicos) que no se corresponden con las típicas nociones binarias sobre los cuerpos masculinos o femeninos. Es decir, intersexual es un término utilizado para describir una amplia gama de variaciones naturales del cuerpo. En algunos casos, los rasgos son visibles al nacer, mientras que en otros no se manifiestan hasta la pubertad. Según lo expresan Oliveira y Rosa (2015):

El descubrimiento de la ambigüedad del genital puede acontecer en dos momentos: en el nacimiento, en caso de que el genital presente una modificación evidente y el médico pueda hacer un diagnóstico. La segunda posibilidad es el descubrimiento tardío, cuando, por ejemplo, las modificaciones de la pubertad no aparecen (p. 2).

Por tanto, las variaciones cromosómicas de las personas intersexuales pueden no ser físicamente visibles, en absoluto. Según expertos, entre un $0,05 \%$ y un $1,7 \%$ de la población nace con estos rasgos ${ }^{1}$. Es posible comprender, entonces, que la caracterización del sexo desde lo biológico también sea diversa, en el entendido de que la conjugación del proceso cromosómico, en el tiempo, determina el sexo de una persona, más allá de ser hombre y/o mujer.

\section{Género}

El ser humano intenta comprender el ámbito en el cual se encuentra y con base en ello genera un conjunto de imaginarios tendientes a explicar la naturaleza de quienes le rodean. Es importante reconocer nuevas concepciones del entorno y el contexto en el cual subyacen las personas. Márquez (1995) percibe "la razón pedagógica [...] como un tipo de racionalidad comunicativa antidogmática, que induce y proyecta la libertad del otro a través de los saberes" (p. 13). Las posturas imperativas deben ser poco a poco superadas, a pesar de aquellos que estén

1 Definición y análisis de Naciones Unidas. Se encuentra en las páginas: www.ohchr. org, www.unfe.org. 
en contra de los cambios sustanciales a la realidad actual, aquellos que propenden por la no alteración de la misma:

La globalización jurídica neoliberal en curso está reemplazando la tensión muy politizada entre la regulación y la emancipación social por una concepción despolitizada del cambio social, cuyo único criterio es el Estado de derecho y la adjudicación judicial por parte de un poder judicial honesto, independiente, predecible y eficiente (Santos, 2012, p. 72).

A saber, esta es una realidad estandarizada, que establece límites en los criterios de movilidad, permea cualquier posibilidad de variación y sataniza toda postura, idea, conducta o comportamiento, que representen una "alteración" de la misma. El uso de lo jurídico formaliza la no alteración de la institucionalidad y conlleva la mecanización del ser humano; de este modo, su trascendencia en el pilar de la emancipación desaparece y solo importa el beneficio de un sistema regido por el mercado de capitales, sin que medie el reconocimiento a las personas. En razón a esto, para Lamas (2000), es válido afirmar que el género permite la existencia de "un imaginario social con una eficacia simbólica contundente y, al dar lugar a concepciones sociales y culturales sobre la masculinidad y feminidad, es usado para justificar la discriminación por sexo (sexismo) y por prácticas sexuales (homofobia)" (p. 4).

Con base en ello, las características naturales que diferencian a los sexos se tergiversan y son convertidas en instrumentos que legitiman el sometimiento de la masculinidad sobre la feminidad. Para Butler, el género es "el resultado de un proceso mediante el cual las personas recibimos significados culturales, pero también los innovamos" (Lamas, 2000, p. 7), es decir que otras perspectivas ingresan en la discusión gracias a la insubordinación frente al sistema, mediante la razón pedagógica y la deconstrucción personal, a partir de una dialéctica individual.

Sublevarse ante lo que oprime e impide repensar es aceptarse y comprender las diferencias propias del ser humano y del elemento social, 
para reconstruir también realidades sociales. En palabras de Santos (2012):

La crisis de la moderna contractualización consiste en el predominio estructural de los procesos de exclusión sobre los de inclusión. [...] El precontractualismo consiste en bloquear el acceso a la ciudadanía de los grupos sociales que anteriormente se consideraban candidatos a esta y tenían una expectativa razonable de acceder a ella (p. 81).

En consecuencia, la inclusión es peligrosa, en la medida en que propone nuevas formas de compresión e inteligibilidad, que no deben ser asumidas, ya que ponen en riesgo a la sociedad heterosexual, excluyen y legitiman la no participación e interacción de importantes colectivos sociales diversos.

\section{Orientación sexual}

La razón ha movilizado al ser humano a estadios distintos, en los que cada uno tiene el derecho de comprenderse a sí mismo, lo cual no puede ser transpuesto. Para Foucault, "el sexo no es una fatalidad, es una posibilidad de vida creativa” (Rabinow, 1997, p. 163), es cuando la libertad no está sometida a la ideación dada por las instituciones, sino que más bien debe separarse de lo predestinado, en lo concerniente al desarrollo intrapersonal.

Al entender la orientación sexual como "la dirección del deseo erótico y la afectividad de las personas en razón al sexo o identidad de género de las otras personas", es cuando se identifica a las personas lesbianas y gais: "categorías políticas con que se enuncia respectivamente a las mujeres y a los hombres que dirigen su deseo hacia personas de su 'mismo' sexo". Asimismo, los bisexuales son personas cuya atracción sexual y afectiva se dirige tanto hacia personas de su mismo sexo, como a personas del sexo "opuesto" (Consejería de Derechos Humanos de la Presidencia de la República, Colombia, 2017). 
Con lo enunciado, la pretensión es generar fundamentos necesarios para liberar el sentir y el cuerpo; en ningún caso se busca generar moldes, en los que unos ingresan y otros no. La orientación sexual, propia del ser humano, al interrelacionarse con otros cuerpos y espíritus, es atracción física, emocional y, por tanto, sexual. Según Foucault (1998):

El burdel y el manicomio serán esos lugares de tolerancia [...]. Únicamente allí el sexo salvaje tendría derecho a formas de lo real, pero fuertemente insularizadas, y a tipos de discursos clandestinos, circunscritos, cifrados. En todos los demás lugares el puritanismo moderno habría impuesto su triple decreto de prohibición, inexistencia y mutismo (p. 9).

La superación del significado establecido permite el desarrollo de la sexualidad desde la orientación, unifica el sentir y el cuerpo, sin que medie la exclusión de la orientación sexual.

\section{Identidad sexual}

Entendida como la forma en que cada persona se construye, se define, se expresa y vive en relación con su sexo. Esta existe, cuando un individuo distingue los factores que lo hacen igual a otros, en términos de género, y los factores que lo hacen distinto de otros, desde su orientación sexual. Tal como lo expresa Hughes:

El individuo busca así diferenciarse de los demás, reconocerse a sí mismo y ser reconocido por los demás. La identidad genera un sentimiento de pertenencia a una comunidad particular y de no pertenencia a otra; $y$, aun cuando los individuos se resistan a la categorización, otros les impondrán categorías (Arancibia, 2013, p. 17).

Actualmente, la sociedad ha categorizado a la población LGBTI como un tercer género. Butler (2006) enuncia que, el género no se limita simplemente a las visiones normativas de masculinidad y feminidad, "el género es el aparato mediante el cual tienen lugar la producción y normalización de lo masculino y lo femenino junto con las formas 
intersticiales hormonal, cromosómica, psíquica y performativa que el género asume" (p. 11).

Para lograr mayor claridad, desde lo jurídico, es importante traer a colación el Decreto 762 de 2018, en cuanto a definiciones conceptuales, tratadas en el artículo 2.4.4.2.1.10:

1. Orientación sexual: atracción sexual, afectiva y erótica, que una persona siente hacia otras de su mismo género, del género opuesto, de ambos, o que no sienten atracción por ninguno de los géneros.

2. Identidad de género: hace referencia a la vivencia personal e individual del género. Es independiente al sexo asignado al momento del nacimiento.

3. Intersexualidad: se trata de una variación orgánica, bajo la cual el desarrollo del sexo cromosómico, gonadal o anatómico, no coincide con los dos sexos que tradicionalmente se asignan.

Este aparte del texto incluye discernimientos conceptuales, sociales y jurídicos, que aportan a una discusión hasta ahora muy poco difundida públicamente.

\section{Principios de Yogyakarta, instrumento internacional para una inclusión de la diversidad sexual}

Todos los Estados deben respetar y legislar por una efectiva igualdad ante la ley, una libertad de ser - por el simple hecho de ser personas-, con dignidad y respeto por la diversidad. Esta revisión jurídica de carácter internacional no solo es vislumbrada desde lo legalista, al contrario, pretende ser resultado de una visión dialógica en lo social, lo cual legitima las acciones de regulación colectiva.

Por ello, desde hace aproximadamente tres décadas, en Colombia, la población LGBTI avanza en la consolidación de su reconocimiento, gracias a significativos logros en cuanto a su seguridad jurídica. Según Onufer et al. (2007): 
Las normas legales internacionales vinculantes que todos los Estados deben cumplir prometen un futuro diferente en el que todas las personas, habiendo nacido libres e iguales en dignidad y derechos, puedan realizar esos valiosos derechos que les corresponden por su nacimiento (p. 7).

Este resarcimiento de derechos es defendido conforme estándares internacionales como los Principios de Yogyakarta, los cuales determinan su indivisibilidad y la condición de ser inherentes a cualquier persona y permiten su desarrollo con base en la dignidad humana. Con este propósito, requieren la deconstrucción del lenguaje normativo, buscan la inserción social y persiguen que la normatividad esté al servicio del reconocimiento social y no que el ser humano esté supeditado a los preceptos heteronormativos, como observaremos a continuación en la exposición de algunos de estos principios.

\section{Disfrute universal de los derechos humanos}

Todo ser humano tiene derecho a gozar de la totalidad de sus derechos, sin abuso de los mismos, a ser percibido y tratado jurídicamente en las mismas condiciones que a los demás (mientras su situación lo permita), en tanto que "todos los seres humanos nacen libres e iguales en dignidad y derechos. Los seres humanos de todas las orientaciones sexuales e identidades de género tienen derecho al pleno disfrute de todos los derechos humanos" (Primer principio de Yokarta).

\section{Los derechos a la igualdad y a la no discriminación}

Todos los seres humanos, sin importar su orientación sexual, deben ser respetados y deben tener los mismos derechos y no recibir ninguna clase de trato diferenciado, que los haga sentir inferiores o vulnerados. Por ello:

[se] adoptarán todas las medidas apropiadas a fin de garantizar el desarrollo adecuado de las personas de diversas orientaciones sexuales e identidades de género, según sean necesarias, para garantizarles a estos 
grupos o personas el goce o ejercicio de los derechos humanos en igualdad de condiciones. Dichas medidas no serán consideradas discriminatorias (Segundo principio de Yokarta).

A partir de la descolonización del cuerpo y el sexo de las instituciones - efecto del debate social-, los seres humanos trascienden, los acervos de poder son pretéritos y la disertación genera aceptación: cambia la institucionalidad.

\section{El derecho al reconocimiento de la personalidad jurídica}

Desde el momento en que nace, a ninguna persona se le puede impedir la adquisición de cualquiera de los atributos que conforman la personalidad jurídica o de elementos que naturalmente sirven para identificar al ser humano y, por ende, están ligados a este derecho. Mucho menos es válido emplear la orientación sexual de una persona como razón para torpedear el goce del derecho en mención. Se establece entonces que:

Todo ser humano tiene derecho, en todas partes, al reconocimiento de su personalidad jurídica [...]. La orientación sexual o identidad de género que cada persona defina para sí es esencial para su personalidad y constituye uno de los aspectos fundamentales de la autodeterminación, la dignidad y la libertad [...] (Tercer principio de Yokarta).

El reconocimiento de los derechos humanos en los ordenamientos jurídicos posibilita que la población LGBTI pueda demandar su personalidad jurídica.

\section{El derecho a la vida}

El reconocimiento de la existencia de un orden jurídico que, en ocasiones, transgrede el derecho a una vida digna, desde la perspectiva de la identidad y orientación sexual diversa, deriva en que, el órgano legislativo colombiano se vea en la obligación de evolucionar en relación con 
las normas jurídicas que constriñen el libre desarrollo de la personalidad. "Toda persona tiene derecho a la vida. Ninguna persona podrá ser privada de la vida arbitrariamente por ningún motivo, incluyendo la referencia a consideraciones acerca de su orientación sexual o identidad de género" (Cuarto principio de Yokarta).

\section{El derecho a la seguridad personal}

Desde el ordenamiento jurídico, toda persona debe contar con las garantías suficientes para su seguridad, por parte del Estado (poder público), referidas a la protección de la integridad física y moral. En consecuencia, los países:

adoptarán todas las medidas legislativas necesarias para imponer castigos penales apropiados frente a la violencia, amenazas de violencia, incitación a la violencia y hostigamientos relacionados con ella, motivados por la orientación sexual o la identidad de género de cualquier persona o grupo de personas, en todas las esferas de la vida, incluyendo la familia (Quinto principio de Yokarta).

De acuerdo a Colina, de los treinta principios que contempla este instrumento internacional, estos cinco "se adoptaron en una reunión multidisciplinaria de expertos de Derechos Humanos, de 25 países, [...] y fueron relanzados oficialmente en Ginebra, el 26 de marzo de 2007, en una sesión del Consejo de Derechos Humanos de la ONu" (Pulecio, 2011, p. 240). Dado que son considerados universales, toda nación debe ajustar su legislación para garantizarlos, sin discriminación alguna.

\section{Inclusión LGBTI en Colombia desde la jurisprudencia constitucional}

La instauración de un enfoque incluyente para la población LGBTI en Colombia ha sido un logro social y jurídico, cuya parte formal y garantista se evidencia, casi totalmente, en los altos tribunales, en los que sobresale la labor de la Corte Constitucional con un aporte de 105 sentencias y 
dos autos, desde 1991 hasta la fecha del presente escrito. Estos motivan el reconocimiento de derechos en los aspectos que se exponen a continuación.

\section{Identificación jurídica coherente y digna}

La cabeza de la jurisdicción constitucional inició su investigación en torno a los derechos de la población LGBTI a través de la sentencia T-594 de 1993, primera providencia del tema, en la cual se le permite a una persona transexual cambiar su nombre de nacimiento por uno que concuerde con su verdadera identidad, con lo que se garantiza el derecho al libre desarrollo de la personalidad como fundamento principal para su decisión. A esta sentencia, le siguió el proceso del derecho a la identidad y el libre desarrollo de la personalidad, gracias a fallos como la T-977 de 2012, que permitió a una mujer transexual cambiar su nombre por segunda ocasión, y la T-611 de 2013, que alude al mismo tema.

\section{Derecho a manifestar la orientación sexual en público}

Conocido coloquialmente como "salir del closet". La sentencia T-539 de 1994 es el punto de partida de la equidad entre parejas homosexuales y heterosexuales, pues delibera sobre un comercial, vetado por el Consejo Nacional de Televisión, en el que aparecían dos hombres que manifestaban conductas propias de una orientación homosexual. La Corte consideró correcta la decisión de la autoridad televisiva, porque el objeto del comercial era prevenir a la población general del Sida; así que, la razón para vetarlo no fue la demostración pública de su homosexualidad, sino el enfoque erróneo que se compartía a los televidentes, ya que la enfermedad aludía a un problema de salud pública que puede afectar a cualquier persona, independientemente del sexo, género, orientación e identidad sexual. La sentencia advierte que "los homosexuales no pueden ser objeto de discriminación", pues, "el hecho de que su conducta sexual no sea la misma que adopta la mayoría de la población, no justifica tratamiento desigual”.

Esta postura ha sido reiterada en otros momentos, como en la T-268 de 2000, cuando la Corte hace un llamado de atención al alcalde de la 
ciudad de Neiva por no otorgar el permiso para hacer un desfile gay; la T-301 de 2004, que ordena a la Policía de Santa Marta dejar de hostigar a los homosexuales que visitaban la bahía de la ciudad; la T-314 de 2011, que analiza la negativa del Hotel Tequendama a permitir el acceso de homosexuales a dos eventos que se celebraban en sus instalaciones; la T-909 de 2011, que ordena a los funcionarios del centro comercial Cosmocentro en Cali y a su empresa de vigilancia hacer un curso, gracias al cual pudieran aprender a proporcionar un trato incluyente a los homosexuales, sin reprochar sus demostraciones públicas de afecto. A esta lista se suman la T-622 de 2010, la T-062 de 2011 y la T-673 de 2013.

\section{Inclusión educativa}

En razón a la discriminación contra la población LGBTI dentro de las aulas, soportada por estudiantes y profesores (la mayoría homosexuales) ${ }^{2}$, la Corte ha estudiado varios casos. La primera sentencia que analizó este eje temático fue la T-097 de 1994, en la cual, el alto Tribunal reprochó al director de la Escuela de Carabineros Eduardo Cuevas García por expulsar a un alumno gay.

Posteriormente, la sentencia T-569 de 1994, si bien no tuteló los derechos de un estudiante que fue vestido de mujer a su colegio, reconoció el derecho al libre desarrollo de la personalidad, sobre el cual, se pronunciaría con mayor vehemencia la C-481 de 1998, que invalidó una norma que señalaba al "homosexualismo" como causal de mala conducta en el ejercicio de la profesión docente.

Este argumento se reitera en sentencias como la T-101 de 1998, que protegió a dos menores de edad hostigados por las directivas de su colegio a causa de su orientación sexual (gais). Así mismo, la T-435 de 2002 manifiesta que "la orientación sexual es una clara manifestación y

2 Toda la población LGBTI ha sufrido la exclusión social, sin embargo, dado que las personas homosexuales representan el componente más amplio - tanto gais como lesbianas-, dentro de la jurisprudencia de la Corte Constitucional, existen más casos en los ellos que están involucrados. 
materialización del ejercicio del derecho al libre desarrollo de la personalidad”. De modo que, la institución educativa no puede coartar esta condición humana, aun cuando alegara la enseñanza de un modelo ético homogéneo para la totalidad de sus estudiantes, ya que esto representaría un evidente caso de intolerancia y represión, lo cual excede los fines verdaderos del servicio público prestado y de la entidad misma. A su vez, la T-565 de 2013 defendió a un menor de edad que se presentó en el colegio vestido según su identidad sexual, con lo cual otorgó valor a la libertad del desarrollo personal sobre el reglamento institucional.

\section{Fuerzas militares}

En relación con la incorporación de personas que hacen parte de la población LGBTI a las diferentes instituciones de esta naturaleza, el debate es complejo, dados los conceptos y principios que tradicionalmente se inculcan en las mismas. La Corte declaró inconstitucional la norma que señalaba como una "falta al honor militar" la realización de "actos homosexuales”. Por ello, la C-431 de 2004 estableció como inconstitucional algunos apartes del Reglamento de las Fuerzas Militares; de igual forma, la T-476 de 2014 eximió a las mujeres transexuales del requisito de la libreta militar.

\section{Cambio de sexo}

Desde 1995, surgieron transformaciones normativas para la solicitud de reasignación de sexo. La primera sentencia fue la T-477 de 1995, en la cual, la Corte hizo un fuerte llamado de atención a un grupo de médicos por reasignarle el sexo a un menor de edad, sin contar con su consentimiento. Más adelante, la sentencia T-876 de 2012 avanza cuando le concede a una persona el derecho al cambio de sexo, así como lo hace la T-918 de 2012, al señalar que:

[...] cobra vital importancia la salvaguarda de sus derechos fundamentales al libre desarrollo de la personalidad, a la autodeterminación y la dignidad 
humana, por cuanto el Estado no puede interponer barrera alguna para que el individuo decida su desarrollo vital, su modo de ser y su condición sexual.

\section{Reconocimiento y protección de la comunidad intersexual}

En este asunto, la Corte ha brindado protección a diversas personas de la comunidad intersexual, mediante varias sentencias, entre ellas la SU-337 de 1999, que reconoce que estas personas constituyen "una minoría que goza de especial protección del Estado”. Luego vinieron varias sentencias sobre el derecho al consentimiento informado, respecto al proceso médico para tratar a los menores de edad intersexuales. Por ejemplo, los fallos T-692 de 1999, T-551 de 1999, T-1390 de 2000, T-1025 de 2002, T-1021 de 2003 y T-912 de 2008, cuyo denominador común es uno solo: la protección de una población históricamente excluida.

\section{Seguridad social}

Aunque la Corte Constitucional ha avanzado en la protección de las personas LGBTI en el acceso al trabajo y la seguridad social, este también es un debate inacabado, entre otras razones, porque involucra el matrimonio homosexual. En tres sentencias, la Corte produjo fallos, los cuales no deciden a fondo frente a esta discriminación: T-999 de 2000, T-1426 de 2000 y T-618 de 2000. No obstante, en la SU-623 de 2001, manifiesta que es "una clara vulneración del derecho a la igualdad, la negativa de una entidad de afiliar a una persona en razón de su orientación sexual".

Luego, vinieron varias sentencias que fueron escalando hacia la igualdad: la T-152 de 2007, que reprochó la discriminación contra una persona transexual en el trabajo; la T-856 de 2007, que permitió afiliar a su pareja del mismo sexo como beneficiaria en el sistema de salud; la C-336 de 2008, que facultó la sustitución pensional del compañero permanente del mismo sexo y la T-1241 de 2008, que reconoció el derecho a la pensión de sobrevivientes. 
Igualmente, la C-029 de 2009 analizó veintiocho leyes demandadas y reconoció los derechos de las parejas LGBTI con un argumento claro: "la pareja [...] goza de protección constitucional, independientemente de si se trata de parejas heterosexuales o parejas homosexuales". En torno a esta idea, surgen la T-911 de 2009, la T-051 de 2010, la T-716 de 2011 y la C-238 de 2012.

\section{Conformación familiar}

En este ámbito, las discusiones son interminables, debido a múltiples diferencias perceptivas y estigmas colectivos. Los pronunciamientos de esta Corte son todavía motivo de fuertes críticas por parte de importantes sectores políticos, sociales y religiosos; tanto así, que los primeros fallos en esta materia son bastante nuevos. Un antecedente importante es la sentencia C-577 de 2011, que reconoce que una pareja homosexual también es considerada una familia, con lo que derriba una gran cantidad de tesis opositoras. Sin embargo, esto no es lo más revolucionario de la jurisdicción constitucional, pues, en el mismo fallo, la Corte menciona la posibilidad del matrimonio entre parejas del mismo sexo y delega al Congreso de la República la tarea de regular el asunto (lo que a la fecha no ha sucedido).

El reconocimiento al derecho de una familia no se limita a la pareja, también aborda la adopción, con base en los derechos de los niños, niñas y adolescentes. Uno de los antecedentes dentro de esta categoría es la sentencia T-276 de 2012, que reprende al Instituto Colombiano de Bienestar Familiar (ICBF) por negar el trámite de adopción de dos niños a un periodista estadounidense homosexual.

Finalmente, la SU-617 de 2014 abrió la puerta a la adopción consentida, es decir, a la posibilidad de que una persona homosexual adopte al hijo biológico de su pareja, bajo el requisito de que los tres hayan convivido durante un tiempo no menor a dos años. Hasta el momento, esto es lo más lejos que la Corte Constitucional ha llegado en términos de conformación familiar. 


\section{Reflexión y conclusiones}

Desde los años noventa, la comprensión, el estudio y la conceptualización de la diversidad sexual, existente en todas las sociedades del mundo, ha tenido importantes transformaciones en el litigio originario, en naciones donde, al parecer, existe mayor libertad de criterios en asuntos normativos. Es por eso que Lind y Arguello afirman que, "la lucha por los derechos de las personas con una identidad de género diferente se ha hecho más visible" (Rodríguez y Valenzuela, 2011, p. 24).

Maurer-Starks et al. (2008) mencionan que "la heteronormatividad es definida como un entendimiento cultural, en el cual la heterosexualidad es la norma y las instituciones sociales resultantes de dicha norma están basadas en el supuesto de que los hombres sienten atracción hacia las mujeres y viceversa" (p. 327). No obstante, la lucha por los derechos de los colectivos LGBTI en el mundo ha logrado avances significativos, gracias a cruentas manifestaciones, que han sido escuchadas por organismos internacionales -entre ellos, algunas asociaciones de médicos-, que han asumido el rol de voceros, desde lo científico, lo jurídico y lo social. Todos ellos han procurado resarcir y/o reconocer los derechos que le asisten a esta comunidad, que ha conseguido reestructurar la doctrina en torno a la orientación e identidad sexual, de las personas LGBTI.

El respeto por la orientación sexual hace posible que los individuos puedan definir con dignidad su identidad sexual y dejar a un lado el discurso homofóbico y de odio. Martínez (2009) manifiesta que "la homosexualidad deja de considerarse un problema personal y pasa a tratarse como una cuestión pública", en un intento por "rediseñar socialmente la percepción de la sexualidad de toda la humanidad" (p. 409). De igual manera, Tozzi (2007) expone la obligación de los Estados de "velar por el cumplimiento de este nuevo mandato [lo cual] se utilizaría para prohibir la expresión de ideas y argumentos contrarios a la ideología de género" (p. 127). 
En cuanto a políticas públicas, para Pulecio (2011):

las violaciones sistemáticas a los derechos humanos hacia las personas de distinta orientación sexual o identidad de género son una constante en sociedades machistas y excluyentes como la nuestra, y la cantidad de vidas que no logran disfrutar de sus libertades fundamentales por esta causa es una realidad que permanece oculta a los ojos de la ciencia jurídica (p. 241).

Al parecer, las limitaciones en los países llamados "en vía de desarrollo" son notorias, aun cuando sean partícipes del ámbito internacional, que proclama la inclusión e igualdad para todos, sin ningún distingo. Un ejemplo de esto es África, en donde, según postulados de Grecko (2011), los grandes líderes políticos ugandeses, apoyados por la sociedad en general, avalan y promueven iniciativas legislativas en contra de la población LGBTI. Algunos pastores religiosos como Martin Seempa, quien celebra reuniones en las que exhibe pornografía gay a miembros de su congregación (dentro de los cuales hay menores de edad), con el fin de diseminar el odio hacia el colectivo LGBTI y advertir sobre un supuesto complot de los homosexuales para reclutar a la juventud (pp. 1-10). Así mismo, en Argentina, Pecheny enfoca la realidad de las minorías sexuales de la nación, al plantear la hipótesis de que las políticas públicas

en materia de igualdad sexual tienen ciertos límites que les son intrínsecos en cuanto a su alcance, dado el objeto y los sujetos de estas políticas. De esta manera, señala que las políticas públicas tienen dos aspectos principales: por un lado, son programas de intervención que implican fundamentos, planes, puestas en obra, evaluaciones; por otro lado, expresan la opinión del Estado sobre una controversia en debate (Rodríguez y Valenzuela, 2011, p. 30).

Tan solo hace tres décadas es permitido el diálogo sobre los derechos de la población LGBTI. Uno de los mayores logros internacionales al respecto son los Principios de Yogyakarta, revisados y aceptados por los Estados parte, presentes en las Naciones Unidas (ONU), compartidos a todos los países miembros, con fines de adición y futura modificación 
de la normativa interna, como en el caso de Colombia. Estos principios son el soporte de los debates sobre derechos humanos de este colectivo, debido a su fuerza teórica y jurídica; con base en ellos, se plantean profundos cuestionamientos a los Estados frente a la urgente necesidad de reorientar o crear un marco jurídico, que permita la seguridad jurídica de quienes son ciudadanos LGBTI.

En Colombia existen 105 tutelas y dos autos de la Corte Constitucional, desde 1991 a la fecha, en los cuales, el honorable colegiado de magistrados observa y aplica las normas internacionales en materia de derechos humanos, por las motivaciones en común, la salvaguarda del derecho a la igualdad y la lucha contra la discriminación. Este es el momento de superar uno de los escollos relacionados con la efectiva inclusión, las garantías y la igualdad de la población LGBTI, desde la pluralidad constitucional y político-administrativa, las normas internacionales, la tendencia y la demanda social.

\section{Referencias}

Arancibia, Cecilia (2013). La oferta turística del Gran Mendoza para el segmento LGBT. Tesis de grado de Licenciatura en Turismo. Recuperada de https:// bit.ly/2ReBnDd

Audí, Laura (2001). Fisiología de la diferenciación sexual. En Juan Pedro López Siguero (Coord.), Estados intersexuales e hipogonadismo, $7^{\circ}$ Curso de Formación de Postgrado. Bilbao: Sociedad Española de Endocrinología Pediátrica

Buttler, Judith (2006). Regulaciones de género. Revista de Estudios de Género. La Ventana, 23, 7-35.

Consejería de Derechos Humanos de la Presidencia de la República, Colombia (2017). Orientación sexual, identidad de género y Derechos Humanos. ¡Sus derechos valen! Recuperado de https://bit.ly/2CVciEH

Corte Constitucional. Sentencia T-476 de 2014. M. P.: Alberto Rojas Ríos.

Corte Constitucional. Sentencia T-477 de 1995. M. P.: Alejandro Martínez Caballero. 
Corte Constitucional. Sentencia C-481 de 1998. M. P.: Alejandro Martínez Caballero. Corte Constitucional. SU-337 de 1999. M. P.: Alejandro Martínez Caballero. Corte Constitucional. Sentencia T-551 de 1999. M. P.: Alejandro Martínez Caballero. Corte Constitucional. Sentencia T-268 de 2000. M. P.: Alejandro Martínez Caballero. Corte Constitucional. Sentencia T-1390 de 2000. M. P.: Alejandro Martínez Caballero. Corte Constitucional. Sentencia T-618 de 2000. M. P.: Alejandro Martínez Caballero. Corte Constitucional. Sentencia T-977 de 2012. M. P.: Alexei Julio Estrada. Corte Constitucional. Sentencia T-1426 de 2000. M. P.: Álvaro Tafur Galvis. Corte Constitucional. Sentencia T-692 de 1999. M. P.: Carlos Gaviria Díaz. Corte Constitucional. Sentencia C-336 de 2008. M. P.: Clara Inés Vargas Hernández. Corte Constitucional. Sentencia T-1241 de 2008. M. P.: Clara Inés Vargas Hernández. Corte Constitucional. Sentencia T-097 de 1994. M. P.: Eduardo Cifuentes Muñoz. Corte Constitucional. Sentencia T-301 de 2004. M. P.: Eduardo Montealegre Lynett. Corte Constitucional. Sentencia T-101 de 1998. M. P.: Fabio Morón Díaz. Corte Constitucional. Sentencia T-999 de 2000. M. P.: Fabio Morón Díaz. Corte Constitucional. Sentencia C-577 de 2011. M. P.: Gabriel Eduardo Mendoza Martelo. Corte Constitucional. Sentencia T-673 de 2013. M. P.: Gabriel Eduardo Mendoza Martelo. Corte Constitucional. Sentencia C-238 de 2012. M. P.: Gabriel Eduardo Mendoza Martelo. Corte Constitucional. Sentencia T-569 de 1994. M. P.: Hernando Herrera Vergara. Corte Constitucional. Sentencia T-856 de 2007. M. P.: Humberto Antonio Sierra Porto. Corte Constitucional. Sentencia T-1021 de 2003. M. P.: Jaime Córdoba Triviño. Corte Constitucional. Sentencia T-912 de 2008. M. P.: Jaime Córdoba Triviño. Corte Constitucional. Sentencia T-276 de 2012. M. P.: Jorge Ignacio Pretelt Chaljub. 
Corte Constitucional. Sentencia T-314 de 2011. M. P.: Jorge Iván Palacio.

Corte Constitucional. Sentencia T-918 de 2012. M. P.: Jorge Iván Palacio.

Corte Constitucional. Sentencia T-909 de 2011. M. P.: Juan Carlos Henao Pérez.

Corte Constitucional. Sentencia T - 062 de 2011. M. P.: Luis Ernesto Vargas Silva.

Corte Constitucional. Sentencia T-565 de 2013. M. P.: Luis Ernesto Vargas Silva.

Corte Constitucional. Sentencia T- 716 de 2012. M. P.: Luis Ernesto Vargas Silva.

Corte Constitucional. SU-617 de 2014. M. P.: Luis Guillermo Guerrero Pérez.

Corte Constitucional. Sentencia C-431 de 2004. M. P.: Marco Gerardo Monroy Cabra.

Corte Constitucional. Sentencia T-051 de 2010. M. P.: Mauricio González Cuervo.

Corte Constitucional. Sentencia T-911 de 2009. M. P.: Nilson Pinilla.

Corte Constitucional. Sentencia T-622 de 2010. M. P.: Nilson Pinilla.

Corte Constitucional. Sentencia T-876 de 2012. M. P.: Nilson Pinilla.

Corte Constitucional. Sentencia T-611 de 2013. M. P.: Nilson Pinilla.

Corte Constitucional. SU-623 de 2001. M. P.: Rodrigo Escobar Gil.

Corte Constitucional. Sentencia T-435 de 2002. M. P.: Rodrigo Escobar Gil.

Corte Constitucional. Sentencia T-1025 de 2002. M. P.: Rodrigo Escobar Gil.

Corte Constitucional. Sentencia T-152 de 2007. M. P.: Rodrigo Escobar Gil.

Corte Constitucional. Sentencia C-029 de 2009. M. P.: Rodrigo Escobar Gil.

Corte Constitucional. Sentencia T-594 de 1993. M. P.: Vladimiro Naranjo Mesa.

Corte Constitucional. Sentencia T-539 de 1994. M. P.: Vladimiro Naranjo Mesa.

De Sousa Santos, Boaventura (2012). Derecho y emancipación. Quito: Editorial Corte Constitucional para el Periodo de Transición.

Foucault, Michel (1998). Historia de la sexualidad I. La voluntad del saber. Coyoacán: Editorial Siglo XXI Editores. 
Grecko, Témoris (2011). Uganda, en el nombre del odio. Esquire Latinoamérica. Recuperado de https://bit.ly/2CVCXRL

Lamas, Marta (2000). Diferencias de sexo, género y diferencia sexual. Cuicuilco, 18 (7), 1-24.

Márquez, Álvaro (1995). La crisis de la modernidad y la razón pedagógica. Frónesis, 2 (2), 1-21.

Martínez, Juan (2009). Igualdad jurídica y género. Anuario de Derechos Humanos. Nueva Época, (10), 389-434.

Maurer-Starks, Suanne; Clemons, Heather y Whalen, Shannon (2008). Managing heteronormativity and homonegativity in athletic training: in and beyond the classroom. Journal of Athletic Training, 3 (43), 326-336.

Ministerio del Interior (2018). Decreto reglamentario 762. Recuperado de https://bit.ly/2Fg9Iul

Oliveira, Ana y Rosa, Marcia (2015). Intersexualidad: una clínica de la singularidad. Revista Bioética, 23 (1), 70-79.

Onufer, Sonia; Muntarbhorn, Vitit et al. (2007). Principios de Yogyakarta. Principios sobre la aplicación de la legislación internacional de derechos humanos en relación con la orientación sexual y la identidad de género. Recuperado de https://bit.ly/2iBpGov

Pulecio, Mauricio (2011). Teoría y práctica de los principios de Yogyakarta en el derecho internacional de los Derechos Humanos. Revista Análisis Internacional, 3, 239-259.

Rabinow, Paul (1997). The essential works of Michel Foucault. Ethics subjetivity and truth, 1, Robert Hurley (trad.). Nueva York: Editorial The New Press.

Rodríguez, Angie y Valenzuela, Edna (2011). Análisis semántico del discurso sobre diversidad sexual y sobre la política pública LGBT en la Pontificia Universidad Javeriana (Tesis de grado de la Licenciatura en Lenguas Modernas). Recuperada de https://bit.ly/2GYc7w8

Tozzi, Piero (2007). Six Problems with the Yogyakarta Principles. International Organizations Research Group Briefing Paper, 1 (s. p.). 